\title{
Attributes of Aliveness: A Case Study of Two Interactive Public Art Installations
}

\begin{abstract}
What elements make people think that an interactive public art installation seems "alive"? To answer this question, the paper examines the design and the reception of two public artworks by the INVIVIA studio: MIMMI and PULSUS. Both are responsive installations that aggregate collective data and interpret it through elements such as vibrations, lighting, and/ or mists, but differences in design decisions have led to different perceptions of their aliveness. Through the case study, this paper identifies key attributes in an installation that contribute to the sense of aliveness and discusses the importance of considering aliveness in design. While these attributes are distilled from public art examples, they can generally apply to designed objects that are, through technological augmentation, physically interactive at the human scale.
\end{abstract}

\section{Keywords}

Aliveness, Perception, Human-Technology Interaction, Technological Augmentation, Public Art Installation

\section{Introduction}

What makes an interactive public art installation seem "alive"? The question of perception of aliveness has been explored by many interaction researchers. The criteria for perceived aliveness has changed over the years, shifting from autonomous motion, to independent intelligence, to possession of the capacity for reciprocal connection [1] and the ability to share control with the human actor as a co-agent in negotiation [2].

In this research context, this paper presents a case study of two public art installations to investigate how design decisions led to different perceived levels of aliveness as experienced by visitors. Through this case study, the paper identifies key attributes in an installation that contribute to the sense of aliveness and discusses the importance of considering aliveness in design.

\section{Case Study of Two Installations}

To investigate what qualities might contribute to the aliveness of interactive public art installations and how people respond to these qualities, this paper presents two public art installations - MIMMI and PULSUS - designed by the INVIVIA studio and on which the authors have collaborated.

\subsection{MIMMI}

Overview. The first case was MIMMI [fig. 1], the winning entry to the 2013 Creative City Challenge Art in the Plaza competition in Minneapolis [3]. It was a large air-pressurized sculpture hovering over the Convention 


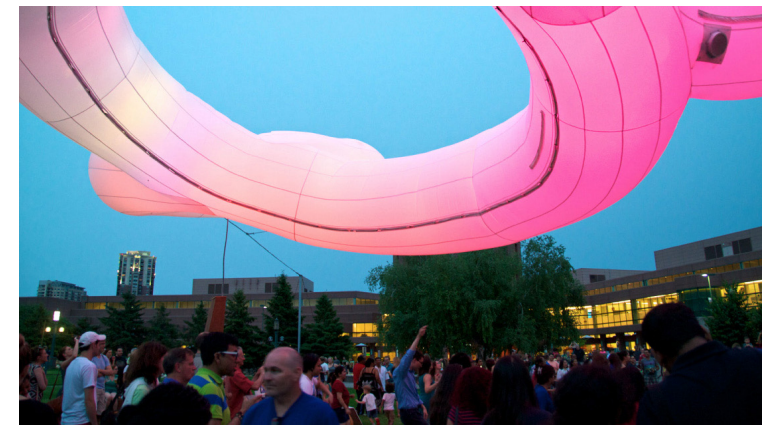

Fig. 1. Installation view of MIMMI.

Center Plaza. It analyzed real-time emotive information gathered via Twitter from city residents to create changing light displays and mists in response.

Design. MIMMI was designed to be a round, light, cloud-like presence in the middle of the plaza. The installation responded to moods of the city with colored lights and mists. The core algorithm aggregated real-time geotagged tweets from the city, evaluated their emotive state, and translated that state into a dynamic microclimate under the suspended structure.

Responses. The experience was described by visitors as "immersive" and evocative of "wonder." Some compared the installation to "a magical cloud" to comment on its real-time responsiveness. Given the narrative of translating the emotional state of the city, a group of visitors held a yoga session underneath the structure in hope of bringing calming change to the installation and taking advantage of the (literal) mood lighting. The overall sentiment was that MIMMI was a thing that had become "enchanted," as if its qualities of wonder were given to it rather than them being intrinsic. Descriptors specifically related to aliveness were not mentioned.

\subsection{PULSUS}

Overview. The second case was PULSUS [fig. 2], an interactive installation commissioned as part of the 2017 SummerStreets Festival in Manhattan [4]. The large concrete sculpture acted as both a bench and an urban instrument that reflected the activity level of its surroundings. It gathered real-time digital activity of the city and reinterpreted it into an immersive experience with vibrations, mists, and sounds. It was installed in

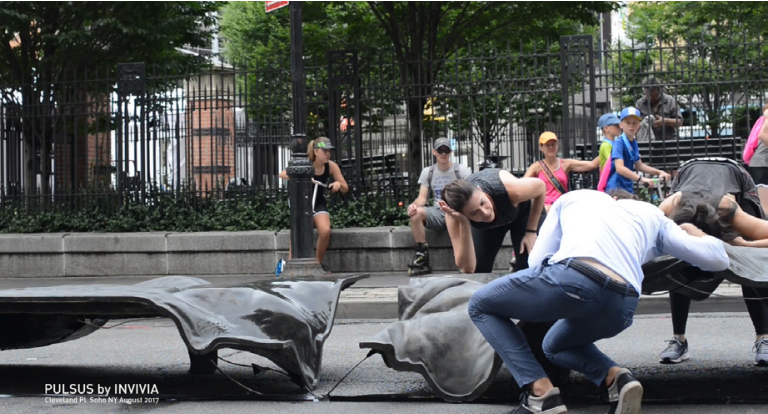

Fig. 2. Installation view of PULSUS (in NYC).

NYC for three weeks before relocating to the Harvard Graduate School of Design for six months.

Design. PULSUS consisted of a series of four sections with each piece made through a fabric-form process with mannequins, resulting in undulations that suggested human forms both above and beneath the drapes. The sculpture composed a dynamic soundscape based on the digital activity of the city, and the soundscape was transmitted via sound transducers through the concrete as vibrations that were also audible through bone conduction. Through an array of piezo microphones, the sculpture was locally responsive to taps on the surface, eliciting mists from embedded nozzles. The intention was to activate the concrete as an interface and engineer surprises into the act of interacting with an architectural material commonly regarded as weighty and inert.

Responses. The design team initially expressed concerns about how people might find the human figures in the concrete macabre, but many visitors actively interacted with the sculpture as if it were something very much alive. Children playing on it were seen with their ears and bodies pressed against the folds to feel the vibrations of a "lumbering creature." Patting the concrete to trigger the mist, several remarked that it seemed like the sculpture was "breathing." Many visitors were delighted to discover sounds akin to "snoring" when they listened with their heads against the sculpture. Some even lay down and snuggled with the human-like forms. The team did not expected the extent to which those who interacted with the installation described the sculpture with words associated with aliveness. 


\subsection{Different Levels of Aliveness of MIMMI and PULSUS}

At first glance, the forms of the two installations immediately set up different expectations. PULSUS incorporated humanoid forms in its concrete folds and invited expectations that these forms might "breathe" or "snore." The toroidal shapes of MIMMI did not resemble common life forms, so visitors tended not to hold similar expectations of aliveness.

The two installations also offered different potentials for relationship development between the visitor and the sculpture. While both installations aggregated and reinterpreted collective data, PULSUS also offered personal intimacy by inviting visitors to physically sit or lie in the concrete nooks. The visitor and the sculpture could form a one-to-one connection through physical contact, and in return the sculpture offered what Turkle coined as the "fantasy of reciprocation" [1] through vibrations and murmurs. MIMMI did not offer similar opportunities for one-to-one connections; the visitor had to interact with MIMMI as one person among a crowd, and there were no possibilities of physical contact between the visitor and the sculpture.

The interaction mechanisms were not immediately decipherable for either installation, and this mystery contributed to the sense that the sculpture might have minds of their own. To a degree, people understood how they might elicit a response: MIMMI required a tweet, and PULSUS read social media and listened to taps on its surface. But the response pattern was never entirely transparent. For both pieces, the algorithms aggregated and reinterpreted the data with sufficient complexity that the lights and sounds produced were more expressive than translational. The PULSUS tapand-mist mechanism also had an element of randomness in its response delay and duration, rewarding visitors with a level of consistency without becoming entirely predictable.

The different technologies employed in the two installations engaged visitors differently depending on their familiarity with the mechanisms. The light show that illuminated MIMMI was essentially a light projection, a form of technology familiar to the presentday onlooker. In contrast, the sound transduction technology used in PULSUS was less widely known, and this lack of familiarity contributed to a stronger sense of wonder.

\section{Attributes of Aliveness}

The interaction insights are distilled into a set of four attributes that describe the capacity for an installation to be perceived as being alive.

\section{Superficial Resemblance. At a superficial level,} an installation that exhibits formal or gestural characteristics resembling those of known lifeforms invites expectations and perceptions of it being alive.

2. Relational Intimacy. An installation is more likely to seem alive if it offers the capacity for people to interact with it intimately - at the human scale if it is architectural, and in a personal manner if the context is public - and if it suggests reciprocation of that intimacy through its own feedback system.

3. Ambiguous Predictability. Human-technology interactivity should be neither entirely predictable nor entirely random. Ideally, the interaction suggests a logic that entices a person to follow along but maintains some element of chance to keep the person intrigued.

4. Technological Familiarity. The quality of aliveness is highly subjective, and this subjectivity depends on the observer's familiarity with technology. Whether a mechanism is "sufficiently advanced" to be "indistinguishable from magic," as Arthur C. Clarke has put it, depends on prior experience of the person making the distinction.

While these attributes are drawn from two interactive public art precedents, they can generally apply to designed objects that are, through technological augmentation, physically interactive at the human scale. It is important to note that the discussion focuses on aliveness as an embodied, tangible quality not derived from an external source that employs the object as a software agent.

\section{Conclusion}

Over the past two decades, there has been a steady trend toward the development of technologically enhanced things that present themselves as having "states of mind that are affected by their interactions 
with human beings" [1]. As technology in computational systems and artificial intelligence advances, humans will come into more frequent contact with augmentation, and human-technology interaction will become increasingly complex. Thus, the quality of aliveness is important not only because aliveness brings playfulness, a quality attractive to humans, but also because understanding what makes something seem alive will help people build stronger rapport with objects or installations. Designers can use these attributes of aliveness as first-steps in considering their role and responsibility in fostering and mediating this potential relationship.

\section{References}

1. Turkle, S. (2006, July 15). Artificial Intelligence at 50: From Building Intelligence to Nurturing Sociabilities. In Dartmouth Artificial Intelligence Conference, Hanover, NH. www.mit. edu/ sturkle/ai@50.html

2. Ackermann, E. K. (2005). Playthings That Do Things: A Young Kid's "Incredibles". In Proceedings of the Conference on Interaction Design for Children, Boulder, CO: ACM. www.childresearch.net/resource/research/2005/playthings. pdf

3. Meet Minneapolis. (2013, June 4). MIMMI comes to Minneapolis Convention Center Plaza Thursday. Retrieved June 1, 2019, from www.minneapolis.org/media/newsreleases/mimmi-comes-minneapolis-convention-centerplaza/

4. INVIVIA. (2018). PULSUS. Retrieved June 1, 2019, from www.invivia.com/portfolio/pulsus/ 